\title{
THE LINIMENTS OF THE U. S. P. AND THE NATIONAL FORMULARY.
}

THOMAS LATHAM, NEW YORK.

The U. S. P. contains eight formulas for liniments, the N. F. an equal number. Though comparatively unimportant as medicinal agents, liniments are frequently dispensed and would long since have been discarded from works of authority were they considered by the medical profession to be entirely useless. I will not attempt a classification of liniments from the point of view of the physician, nevertheless the pharmacist must possess a certain knowledge of their effect when applied to the skin so as to avoid misadventure in their use.

\section{I.inimentum Ammonie, U. S. P.}

Ammonia Water ..................... $350 \mathrm{cc}$.

Alcohol ........................... 50 cc.

Cotton Seed Oil................... $570 \mathrm{cc}$.

Oleic Acid ...................... $30 \mathrm{cc}$

Suggested formula:

Ammonia Water .................... 400 cc.

Liq. Paraffin Oil................... $550 \mathrm{cc}$

Oleic Acid ........................ $50 \mathrm{cc}$.

The latter remains a constant emulsion, never congealing as when made with vegetable oils. The alcohol is not needed to maintain liquidity.

\section{Linimentum Belladonne, U. S. P.}

Camphor ..................... 50 grams

Fluidextract Belladonna Root, to make........ $1000 \mathrm{cc}$. Suggested formula:

Camphor ........................... 37.5 grams

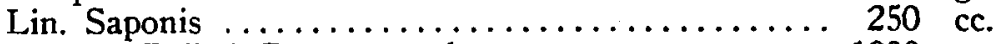

Fl. Ext. Bellad. Root, to make............. 1000 cc.

More lubricant than the U.S. P., therefore easier to apply, and the camphor is in better solution. This liniment is rarely used alone.

\section{Linimentum Calcis, U. S. P.}

The title of liniment scarcely describes this valuable compound, much used under the name of Carron Oil. The lime water should be of the best and placed in the bottle first. On adding the linseed oil in exactly equal volume emulsification takes place at once.

I.inimentum Camphora, U. S. P.

Camphor, in coarse powder............ 200 grams

Cotton Seed Oil...................... 800 grams

Improved by using yellow paraffin oil at one-third the price of cotton seed oil. There is no valid reason for retaining the cotton seed oil.

Linimentum Chloroformi, U. S. P.

Chloroformi .................... $330 \mathrm{cc}$.

Soap Liniment ..................... $700 \mathrm{cc}$.

Too strong in chloroform and too expensive for general sale. 
Suggested formula:

Chloroform ........................... $200 \mathrm{cc}$.

Methyl Salicylate ........................... $50 \mathrm{cc}$

Paraffin Oil, colorless....................... $750 \mathrm{cc}$.

May be colored if desired with soluble anilin green.

\section{Linimentum Saponis, U. S. P.}

Soap, dried and granulated................ 60 grams

Camphor .............................. 45 grams

Oil Rosemary $\ldots \ldots \ldots \ldots \ldots \ldots \ldots \ldots \ldots \ldots, 10$ cc.

Alcohol $\ldots \ldots \ldots \ldots \ldots \ldots \ldots \ldots \ldots \ldots \ldots \ldots, 725$ cc.

Water to make........................ $1000 \mathrm{cc}$.

The directions are to heat the soap on a water bath with the water until a clear gelatinous mass results. To this the alcohol is to be gradually added, having had the other ingredients previously dissolved in it.

Suggested formula: Dissolve the soap in fine powder in the alcohol containing the other ingredients. Any bottle of sufficient capacity may be used and the operation conducted cold and finished in an hour or two. Filtration concludes it.

Linimentum Saponis Mollis, U. S. P.

Soft soap $\ldots \ldots \ldots \ldots \ldots \ldots \ldots \ldots \ldots \ldots \ldots, 650$ grams

Oil of lavender flowers..................... $20 \mathrm{cc}$.

Alcohol to make....................... $1000 \mathrm{cc}$.

Amended by using the cheap methyl salicylate instead of the dear oil of lavender with better covering effect. No need to use imported green soap (which, by the way, is never green), we now having most excellent domestic made with linseed oil at one-fourth the price.

\section{Linimentum Terebinthinae, U. S. P.}

Rosin cerate $\ldots \ldots \ldots \ldots \ldots \ldots \ldots \ldots \ldots \ldots, 650$ grams

Oil of Turpentine...................... 350 grams

Dissolve together with gentle heat.

Suggested formula: Use petrolatum flavum at a much lower price, instead of the rosin cerate, the only purpose of which is to dilute the oil of turpentine.

Linimentum Aconiti et Chloroformi, N. F.

Fld. Ext. Aconite...................... 45 cc.

Alcohol $\ldots \ldots \ldots \ldots \ldots \ldots \ldots \ldots \ldots \ldots \ldots, \quad 80 \mathrm{cc}$.

Chloroform $\ldots \ldots \ldots \ldots \ldots \ldots \ldots \ldots \ldots \ldots \ldots \ldots, 125 \mathrm{cc}$.

Soap Liniment $\ldots \ldots \ldots \ldots \ldots \ldots \ldots \ldots \ldots \ldots, 750 \mathrm{cc}$.

This excellent liniment can be improved by the addition of menthol, 20 grams, in which combination it is a great favorite with physicians.

Linimentum Ammonit Iodidi, N. F.

Iodine $\ldots \ldots \ldots \ldots \ldots \ldots \ldots \ldots \ldots \ldots \ldots, 4$ grams

Oil Rosemary ............................... 15 cc.

Oil Lavender............................ 32 rc.

Ammonia water $. . . \ldots \ldots \ldots \ldots \ldots \ldots \ldots \ldots \ldots, 110$ cc.

Alcohol, to make......................... $1000 \mathrm{cc}$

Suggested formula:

Ammonium Iodide $\ldots \ldots \ldots \ldots \ldots \ldots \ldots \ldots \ldots, \quad 30.00$

Soap Liniment $\ldots \ldots \ldots \ldots \ldots \ldots \ldots \ldots \ldots \ldots \ldots, 1000.00$ 
Linimentum Iodi, N. F.

Can be considered obsolete, as in more than forty years' practice I have never dispensed it or heard of its being dispensed.

Linimentum Opir Comp., N. F.

Tr. Opium ....................... 100 cc.

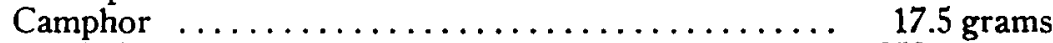

Alcohol .......................... 250 cc.

Oil Peppermint ...................... 25 cc.

Ammonia water ................... 375 cc.

Oil Turpentine, to make................ 1000 cc.

On account of its high price and the comparative uselessness of its expensive ingredients, tincture opium and oil peppermint, the following is recommended:

Suggested formula:

Tr. Opium ........................ $10 \mathrm{cc}$.

Tr. Arnica ......................... 90 cc.

Camphor ....................... $20 \mathrm{cc}$.

Alcohol .......................... 250 cc.

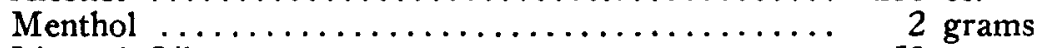

Linseed Oil ...................... 50 cc.

Ammonia Water ..................... $400 \mathrm{cc}$.

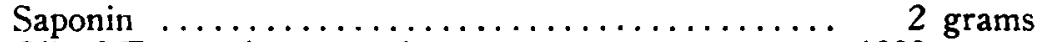

Oil of Turpentine, to make............... $1000 \mathrm{cc}$.

Add the saponin, menthol and camphor to the alcohol, then the linseed oil and ammonia water, the other ingredients following. A fairly perfect emulsion results.

\section{Linimentum Saponato-Camphoratum, N. F.}

This old composition is retained chiefly for historical interest and I cannot remember selling it for thirty years. Opodeldoc Liquid, i. e., Soap Liniment, has taken its place; however, it may be made readily with any of the popular brands of white laundry soap which have a mixed base of cotton seed and cocoanut oil and readily solidify or jelly on cooling.

Linimentum Terebinthinae Aceticum, N. F.

Oil of Turpentine.

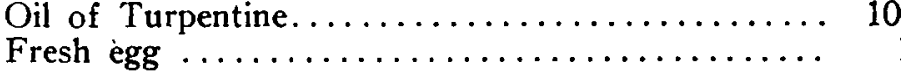

Oil Lemon ....................... 4 cc.

Acetic Acid ...................... 20 cc.

Rose Water ..................... 85 cc.

Suggested formula:

Oil of Turpentine.................. 500 cc.

Water .......................... 500 cc.

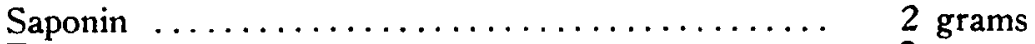

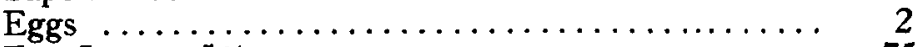

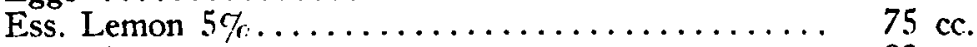

Acid Acet......................... $90 \mathrm{cc}$.

This deservedly popular liniment has stood the test of about 150 years' use, and when properly made is an elegant emulsion. Made by the present N. F. formula, it thickens on standing, needs shaking and often is difficult to pour out of a narrow-necked bottle. 
Linimentum Tiglit and Tiglit Compositum, N. F.

In my experience these have never been used, and have never been in my stock. The oil alone is seldom prescribed; occasionally the physician orders it diluted with olive oil as he desires.

The author also recommends the following formulas as yielding preparations which give good satisfaction:

Analgesic Liguid Balm.

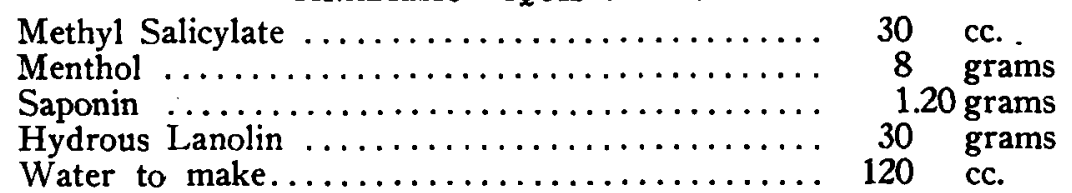

Weigh the lanolin into mortar, dissolve the methyl salicylate, menthol and saponin successively together, triturate with the lanolin and add water gradually to complete an emulsion.

A solid form of the above for tubes can be made with the same ingredients, omitting the water, and substituting cold cream made with liquid paraffin.

UNIVERSITY RUB.

Methyl Salicylate ..................... $1.00 \mathrm{cc}$.

Spt. Camphor $\ldots \ldots \ldots \ldots \ldots \ldots \ldots \ldots \ldots \ldots, 20.00$ cc.

Ext. Witch Hazel........................ 25.00 cc.

Alcohol ......................... $50.00 \mathrm{cc}$.

A favorite with our local athletes.

Boston Liniment, or Veterinary Liniment.

Ess. Oil Mustard....................... $3.00 \mathrm{cc}$.

Oil Turpentine $\ldots \ldots \ldots \ldots \ldots \ldots \ldots \ldots \ldots \ldots, 20.00 \mathrm{cc}$.

Castor Oil $\ldots \ldots \ldots \ldots \ldots \ldots \ldots \ldots \ldots \ldots \ldots \ldots, \quad 10.00 \mathrm{cc}$.

Alcohol $\ldots \ldots \ldots \ldots \ldots \ldots \ldots \ldots \ldots \ldots \ldots .67 .00$ cc.

Tr. Red Saunders to color.

\section{SYRUP OF LACTUCARIUM.}

L. E. SAYRE, LAWRENCE, KAN.

Inasmuch as this preparation nor the drug which is represented is not mentioned in the list of Useful Therapeutic Agents published by the American Medical Association, it would seem that the committee which has charge of the compilation of these Useful Remedies believes it unworthy of notice as a useful therapeutic agent.

Nevertheless, the drug itself has not become obsolete. Corresponding with some of the larger manufacturing houses, I have the following statements to make :

From one of the largest houses, we have the following:

"We submit below the amount of Lactucarium which we have purchased during the past few years:

$$
\begin{aligned}
& \text { 1910-298 lbs. } \\
& 1911-150 \text { lbs. } \\
& 1912-47 \text { lbs. } \\
& 1913 \text { - } 58 \text { lbs. from January 1st to May 19th. }
\end{aligned}
$$

